\title{
A TERCEIRA MARGEM DA HISTÓRIA: estrutura e relato das sociedades indígenas*
}

\author{
Oscar Calavia Sáez
}

A história indígena no Brasil passou para o primeiro plano do interesse dos antropólogos nos anos de $1980 .{ }^{1}$ O tema em si não era novo, mas costumava aparecer nas monografias na forma de um capítulo específico, a saber, o contato com a sociedade dos brancos que a rigor teria trazido a história para um lugar onde ela não se encontrava previamente. A história seria uma somatória de externalidades: frentes de expansão, fricções interétnicas, políticas indígenas e indigenistas, ações da sociedade nacional e reações nativas. Nas monografias, podia crescer até tomar conta da descrição e reduzir a prólogo a descri-

* Este artigo faz parte das atividades do projeto "Transformações indígenas: os regimes de subjetivação ameríndios à prova da história" (NUTI-PRONEX), desenvolvido por equipes do MNRJ e da UFSC.

Artigo recebido em junho/2004

Aprovado em novembro/2004 ção da vida "pré-contato" - distribuição adequada quando se tratava de grupos "aculturados" ou "integrados" -; ou assumir a forma de um epílogo ou de um necrológio, quando pelo contrário os protagonistas eram donos de uma cultura distintiva e ainda vigorosa, cujo crepúsculo mal se iniciava perante os olhos melancólicos do etnógrafo.

Se o capítulo do contato, maior ou menor, prólogo ou epílogo, não perdeu sua importância, o florescimento da história indígena extravasou decerto seus limites, fazendo da história uma dimensão constante e interna das sociedades em pauta. Essa redistribuição atendia a uma necessidade do movimento indígena que na época desabrochava com força (Carneiro da Cunha, 1992). Povos que aspiravam a um futuro deviam ter também um passado, e assumir como própria, e não mais como resultado de uma intromissão, a capacidade de mudança. O movimento da história indígena - e falo em "movimento" porque em vá- 
rios sentidos ultrapassava os limites da academia, inserindo-se nas empresas do próprio movimento indígena - tomou vários caminhos, alternativos ou combinados. De um lado, promoveu uma recuperação e uma avaliação mais otimista do acervo documental produzido ao longo dos séculos pelos agentes da sociedade colonial ou nacional, maior em quantidade e qualidade e muito menos perdido do que era de praxe considerar. Com essa revisão o movimento afirmava, ao mesmo tempo, que o papel dos indígenas na constituição da sociedade nacional era muito mais constante e profundo do que os grandes relatos da "formação do Brasil" deixavam entrever.

De outro, somando-se a uma tendência mundial nos estudos sobre sociedades sem escrita ou sobre setores populares das sociedades letradas, o movimento adotou uma atitude renovada em relação à tradição oral, aceitando seu valor de documento, ou mesmo realçando seu significado como visão alternativa à história oficial. Essa nova legitimidade do oral coadunava-se com uma indagação sobre a percepção indígena da história, e, portanto, da abertura ao que poderia se chamar de "historicidades outras", não necessariamente em acordo com os padrões heurísticos ou cronológicos da historiografia acadêmica.

Em terceiro lugar, e confrontando uma dualidade central na antropologia, o movimento que nos ocupa se detinha sobre as relações entre estrutura e história, debelando as versões estáticas da primeira e as versões entrópicas ou voluntaristas da segunda.

Cada uma dessas vertentes da historiografia dos povos indígenas teve os seus inspiradores e seus autores emblemáticos, não necessariamente afinados entre si, tributários e/ou renovadores de todos os paradigmas teóricos da antropologia. Em comum, havia talvez uma valoração ética da história ou da historicidade. Afirmar que os índios têm e sempre tiveram -, história, equivalia a uma reatualização de reconhecimentos anteriores; o de que eles têm, por exemplo, alma, ou racionalidade.

A afirmação da historicidade indígena assumia também a forma de uma revisão dos pressupostos da antropologia, denunciando essa ficção dos povos sem história cuja autoria era colocada na conta do evolucionismo, do funcionalismo, do culturalismo ou do estruturalismo, dependendo da filiação e das desafeições do crítico. É claro que essa ficção se apresentou de modos muito diferentes, que foram desde a caracterização dos primitivos como um grau zero da humanidade (ou de uma história que ainda não aconteceu), até a descrição de suas sociedades como formações estáveis de fato ou por desígnio próprio, além da alegada impossibilidade de auferir uma história (entendida de modo estreitamente positivista) a partir dos dados disponíveis, ou ainda até o não reconhecimento da continuidade entre formas vigorosamente distintivas e híbridas surgidas da interação com o exterior. Os primitivos podiam ser ahistóricos por natureza, ou por vocação, ou por definição, ou por ignorância invencível acerca do seu passado. Por ser mais recente, ou mais sugestiva, ou mais explícita, a fórmula levi-straussiana da oposição entre sociedades frias e quentes desdobrada em outras: relógios e máquinas a vapor, por exemplo (cf. Charbonnier, 1989, p. 30; Lévi-Strauss, 1987) - foi tomada em muitos casos como antagonista preferente dos arautos da historicidade indígena, uma opção excessiva na medida em que se fazia dessa antinomia um resumo do conjunto das negações.

Deixando de lado, por enquanto, a injustiça dessa leitura do binômio levi-straussiano, é preciso sublinhar que, na decisão desse novo status da história indígena com respeito à história universal, havia também muito dessa caça às dicotomias que rivaliza com a sua formulação pela honra de ser o passatempo preferido dos antropólogos. Dito de outro modo, havia uma ênfase nas continuidades em detrimento dos contrastes. Mesmo que se postulasse a historicidade indígena como "outra historicidade", era no termo "historicidade" e não no termo "outra" que recaia o acento, o que não pode surpreender em uma tendência que reagia contra o exótico.

Mas os estudos sobre história indígena já contam com uma razoável maturidade, e pode se esperar que se libertem de alguns movimentos reflexos dependentes de seu contexto de origem. Nem a afirmação de uma historicidade ecumêni- 
ca, nem a articulação de estrutura e história são bandeiras que necessitem de mais defesa, muito embora haja uma defasagem importante entre sua afirmação genérica e sua aplicação a descrições concretas. A documentação sobre a história indígena passou a ser objeto de uma procura intensa. O movimento indígena vai assumindo como própria - por exemplo, nos textos usados na educação indígena diferenciada - uma historiografia que nem sempre se prende, porém, às pautas daquela "outra historicidade" descoberta pelos etnohistoriadores. Criado um consenso sobre generalidades, talvez seja o momento de se voltar sobre a história indígena e enfocar desta vez não já as suas continuidades com um modo ocidental de palmilhar o tempo, mas precisamente aqueles contrastes que em épocas anteriores permitiam imaginar a existência de povos sem história. ${ }^{2}$

Os Yaminawa foram o tema da minha tese de doutorado (Calavia Sáez 1995), que tentou se aventurar pelas três vertentes da historiografia indígena antes citadas - o resgate da documentação, a definição de uma outra historicidade e a articulação de descrições estruturais e históricas. Em geral, os Yaminawa são um excelente ponto de partida para um balanço. De um lado, estão muito longe de representar aquele modelo cristalino dos povos "sem história", congelados ou seguros na reprodução de suas estruturas. À primeira vista são evidentes sua instabilidade social, a alteração constante de seus assentamentos e dos seus arranjos parentais e a sua mestiçagem. À primeira vista, também, é fácil se decantar por uma avaliação pessimista das suas relações com o mundo em volta. Ao mesmo tempo, esses índios desesperadamente históricos parecem encarar a história com alguma frialdade: fraco record genealógico, escassos vestígios - nomes próprios de personagens ou lugares do passado, marcos temporais - para servir de arcabouço a uma memória coletiva; pouco empenho na transmissão dos saberes. Nas páginas a seguir, pretendo detalhar essas características e traçar um balanço da minha experiência de escrita da história Yaminawa, que pode se estender em alguma medida a outros povos das terras baixas.

\section{A eficácia documental}

Em relação à primeira das vertentes da historiografia indígena - a da reavaliação das fontes documentais -, cabe dizer que o pessimismo que se aplicava ao conjunto dos povos indígenas deveria se manter para um setor considerável destes. Uma busca insistente não conseguiu levantar a respeito dos Yaminawa senão notas jornalísticas esparsas, citações em longos listados de etnias, referências de terceira ou quarta mão, relatos de um encontro fugaz ou estereótipos devidos a etnias vizinhas. Por muito proveito que possa se tirar de semelhante conjunto, trata-se de dados que não nos situam no interior de uma sociedade Yaminawa, mas no interior de um campo étnico no qual o termo Yaminawa ganha sentido. A rigor, dizemnos muito mais da história de um nome do que da história de qualquer povo ligado a ele.

Sobretudo, falta o tipo de documentação densa que podem produzir etnógrafos, missionários ou agentes indigenistas. Essa falta - que persiste até os dias de hoje - pode significar ainda assim alguma coisa, já que missionários, etnólogos ou indigenistas têm produzido uma literatura considerável sobre quase todos os povos que encontramos em volta dos Yaminawa. É o caso dos Shipibo-Conibo, dos Piro, dos Kaxinawá. Que tipo de acaso poderia determinar que os Yaminawa não tenham sido objeto dessa atenção? De fato, sabemos - embora os Yaminawa não lembrem que há missionários católicos que os visitaram com alguma freqüência na década de 1950. Mais próximos, e lembrados por eles, os missionários da missão Novas Tribos do Brasil - MNTB se estabeleceram cerca de vinte anos depois na AI Mamoadate; ocuparam-se muito pouco dos Yaminawa, preferindo concentrar seus esforços nos Manchineri. A Funai, que só em 1975 se instalou no Acre, com meios humanos em geral escassos, constituiu um posto na aldeia Mamoadate, mas nunca o fez na terra indígena das Cabeceiras do Rio Acre, onde desenvolvi minha pesquisa. A documentação sobre o grupo, mesmo nos últimos vinte anos, é escassa. Esse desinteresse persistente, provavelmente decorrente da constatação de que os Yaminawa são um grupo "difícil", indica 
que missões religiosas ou leigas, produtoras por excelência da documentação etnológica não profissional mas de qualidade, fazem consciente ou inconscientemente uma seleção dos objetos de sua descrição. A vasta e longa documentação sobre os grupos Pano ribeirinhos elaborada pelos missionários franciscanos ou seus visitantes (naturalistas, militares, geógrafos, aventureiros, artistas) trata, evidentemente, dos grupos que se instalaram nas missões, e só de um modo muito indireto daqueles que as evitavam permanente ou periodicamente, e essa desatenção é a contrapartida do trabalho etnogenético que se dedica entretanto aos seus vizinhos. As missões, em sentido amplo, têm um papel importante na formação de etnias, e a fortiori da memória histórica dessas etnias. Isso é importante especialmente para os povos Pano ribeirinhos que, parafraseando livremente a sugestão de Frank (1991), podem ser muito bem entendidos como híbridos de uma sociedade local e uma elite exótica. O mesmo podese dizer também, em um registro mais discreto, do papel que o Instituto Lingüístico de Verão ILV cumpre com respeito aos Kaxinawá. ${ }^{3}$ No mínimo, cabe dizer que as etnias "selecionadas" pelas missões têm, nesse diálogo com os seus diversos apóstolos, uma boa oportunidade para inventar a sua cultura, no sentido que Roy Wagner (1975) dá a essa noção, e que muito bem poderia se estender à invenção da história. ${ }^{4}$ No máximo, pode-se supor que a acumulação de uma tradição escrita externa consolida, ou eventualmente cria, uma distinção entre povos "de referência” - que atendem aos requisitos mínimos do que se considera ser uma etnia e uma história - e povos marginais a esse centro. $\mathrm{O}$ contraste entre documentações ricas e pobres - sendo as ricas, necessariamente, aquelas em que os membros de uma etnia jogam um papel ativo, formulando suas memórias - não é um simples gradiente quantitativo, mas o resultado de um processo que introduz divergências qualitativas e distribui papéis diferenciados no campo étnico. A produção, ou a co-produção de documentos é útil para elucidar a história, mas não sem antes ser útil para fazê-la, muitas vezes, paradoxalmente, gerando esse tipo de modelos cristalinos do passado que costumamos entender como a antítese da história.

\section{O sujeito histórico}

Essa questão vincula-se diretamente a uma outra, aparentemente distante, que diz respeito à especificidade da percepção Yaminawa da história. Qual seria o sujeito dessa história? O "nós" Yaminawa - yura, yurawo, isto é, o "corpo", o grupo de parentes/co-residentes que troca alimentos e substâncias corporais - é um sujeito sociológico, mas não um sujeito histórico. Não poderia sêlo, porque uma sociedade cognática como a Yaminawa necessariamente vê esse Yura se cindir ou pelo menos se diluir geração após geração caminho ao passado; segmentos inteiros de uma sociedade "misturada", que são partes constitutivas do seu aqui e agora, formam o exterior no passado recente.

A rigor, nada há nisso de especificamente Yaminawa, ou ameríndio. Qualquer história consciente do caráter construído das identidades enfrenta esse mesmo problema, trate-se de Yaminawa, da França, dos judeus ou dos ciganos. Mas no caso esse contraste entre uma história escrita na primeira ou na terceira pessoa do plural - essa tensão entre o "nós" da atualidade e o "eles" de tempos outros - manifesta-se num limiar muito próximo à enunciação do relato. Para contar com esse sujeito histórico estável, os Yaminawa deveriam, por exemplo, adotar uma norma de unifiliação - e contar sua história em nome de uma linhagem ou se dar à empresa de criar uma identidade retroativa. A segunda solução, padrão nas histórias nacionais, é a seguida por outros povos Pano como os Shipibo-Conibo e os Kaxinawá, ora se identificando com determinados padrões culturais (os da "civilização ucayalina"), ora definindo um critério de identidade (os Huni Kuin, gente verdadeira, tem sua origem narrada num mito, se reconhecem por determinada organização das suas aldeias etc.). Os Yaminawa ignoraram ambas as possibilidades: reconhecem-se num etnônimo que lhes foi atribuído pelos primeiros agentes da Funai que trataram com eles, mas acrescentam que no passado eram Xixinawa e Yawanawa, ou antes Mastanawa e Marinawa, ou Déianawa etc. etc., sendo que todos esses nomes designam povos "outros", diferentes entre si, distantes do narrador. 
Como historiador, minha tarefa foi rastrear em conjunto essas referências e as notícias esparsas em variadas fontes documentais, fazendo o relato não tanto de um "povo", mas de uma determinada posição dentro do campo étnico.

Além dessa história construída por mim, os Yaminawa possuem uma outra (trata-se de um outro tipo de história) que me limitei a recolher e comentar: as histórias dos antigos, chamadas shedipawó. Os Yaminawa, que não se autodenominam - são os outros que os nomeiam -, também não contam sua história senão a de outros, - os antigos. Não obstante o termo shedipawó sugerir um elo de parentesco, podendo ser glosado como "os grandes avôs", deve-se sublinhar que esse parentesco não implica uma identificação. Os yura compartilham netos (um único termo de parentesco engloba todos os indivíduos dessa geração), mas não necessariamente "avós": os antigos não são imaginados como um bloco solidário de ancestrais, mas como uma diversidade incontrolável de eventuais inimigos. O melhor exemplo são os Rwandawa que, se atendermos às interpretações de um dos meus melhores informantes, perfazem uma das "metades" do atual povo Yaminawa, e que nos mitos aparecem constantemente no papel de inimigos semi-monstruosos. De resto, os "grandes avós" não são uma manifestação de força, sabedoria ou moral prístinas, mas protagonistas de um modo de vida insano, inviável; são ignorantes, pobres, violentos (como são também, aliás, alguns contemporâneos. Antes que "ancestrais" são "marginais". Essa falta de sujeito histórico transcendental, ou, mais explicitamente, de um sujeito que seja a um só tempo narrador e agente da história, seria talvez uma característica distintiva de uma história "fria", mas que convive sem problemas com uma consciência de mudança. Examinemo-los mais de perto.

Os shedipawó diferem consideravelmente de um padrão muito comum na história oral, que organiza um continuum de proximidade/distância temporal. Atendendo à habitual taxonomia das narrações, todos eles são inequivocamente "mitos", ou, para usar a econômica definição levistraussiana, histórias do tempo em que os animais falavam. Não há separação entre esse tempo de comunicação universal e um tempo exclusivamente humano. Cronologicamente os shedipawó são planos: a única distinção entre o antes e o depois faz parte de um reduzido grupo de mitos "de origem”. Antes do episódio narrado, os homens faziam o amor na dobra do joelho, as mulheres não sabiam parir, as sementes eram monopolizadas por um personagem sovina etc. Porém, esses mitos de origem, capazes de traçar uma linha divisória entre o pretérito e a condição atual, não servem para fazer dessa linha um marco temporal de validade geral; o antes e o depois se esgotam dentro de cada narração. Não há um retrato diferenciado do que seria uma humanidade primeva em contraste com a atual. Em particular, embora os mitos descrevam o início de algumas capacidades importantes, eles em lugar nenhum descrevem o fim desse regime de transformações e de comunicação entre as espécies que serve de eixo ao conjunto das narrações. Em outras palavras, o fim dos tempos míticos não faz parte desses relatos. Isso é compreensível na medida em que os fatos extraordinários narrados, e que os Yaminawa sabem muito distantes da experiência cotidiana, se identificam mais com uma distância sincrônica do que diacrônica; o tempo em que os animais falam é um outro tempo atual, o do xamanismo.

Se essa fraqueza de conjunto dos mitos de origem neutraliza a dimensão cronológica dos shedipawó, ela reforça também uma característica que convencionalmente marca os relatos históricos por contraste com os míticos. Em poucas palavras, os shedipawó não são senão residualmente relatos paradigmáticos. São apresentados como episódios individuais, que alguma vez aconteceram com um protagonista individual e concreto: os títulos ou os resumos dos shedipawó falam sempre, por exemplo, do homem que se transformou em queixada, ou do grupo que se transformou em queixada, não da origem das queixadas ou da sua caça. Há uma redução daqueles personagens que em outras mitologias mostram um valor exemplar. Em numerosas ocasiões, por exemplo, os mitos são protagonizados por dois irmãos com características mais ou menos gemelares, mas não por isso existe um ciclo de narrações dos gêmeos, nem estes assumem o papel de demiurgos pelo qual se destacam em ou- 
tras mitologias ameríndias. Os shedipawó apresentam-se como fatos que aconteceram uma vez - não como fatos que aconteceram, por assim dizer, de uma vez e para sempre. A considerável liberdade com que são expostos - sem requisitos ou restrições quanto aos narradores, à audiência, às circunstâncias da narração etc. - combina bem com o escasso rendimento social que deles se obtém. Não há esforços para fazer deles histórias exemplares, para consagrar por meio deles hábitos ou normas. Embora o acervo dos shedipawó seja uma fonte inesgotável de referências para os cantos xamânicos ou amorosos, ou para comentários humorísticos sobre a personalidade de um vizinho (tão esfomeado como Yurapibe, que devorou duas esposas, por exemplo), não existe uma atividade de exegese socialmente demarcada que os eleve à categoria de história sagrada. ${ }^{6} \mathrm{Na}$ sua textura mais existencial que essencial, os shedipawó aproximam-se paradoxalmente de um dos principais atributos com que a filosofia do ocidente identifica o histórico.

A mitificação dos fatos históricos representa, suponho, o caso que melhor alimenta a avidez dos defensores da história oral. Depurar o mito de suas fantasias, localizar nele referências que o atrelem a uma narração fiel aos fatos, em suma extrair história do entulho mítico seria uma das tarefas principais do etnohistoriador, e uma das mais produtivas. O caso Yaminawa mostra, no entanto, que essa tarefa pode estar viciada por um pressuposto ingênuo: o de que essa racionalização teria ficado à espera de um estudo formal, o de que gerações e gerações de nativos têm se limitado a uma honesta acumulação de entulho mítico. Nada impede que a mitificação da história e a historização do mito tenham se sucedido regularmente ao longo dos séculos, e é muito provável que, do mesmo modo em que se diz que a história é constantemente inventada, possa se dizer que ela é constantemente trazida à terra pela transformação de relatos paradigmáticos em relatos eventuais.

\section{O homem branco}

Mas estamos nos desviando justamente do tipo de relato que de praxe tem provocado as re- flexões sobre a história indígena, isto é, aquele que diz respeito ao homem branco. Durante a minha pesquisa, de fato, o encontro com o homem branco me foi narrado com freqüência. Sempre me pareceu claro, porém, que não se tratava de um relato shedipawó. Na ausência de uma diferenciação de gêneros narrativos - para a qual os Yaminawa não ofereciam nem muitos subsídios nem muito interesse $^{7}-$, esse relato parece constituir um gênero em si. Trata-se, na verdade, de um único relato que, com variações mínimas de detalhe, é repetido por todos os narradores: no início, os Yaminawa não tinham sal, açúcar, machado de ferro; andavam nus, dispersos na floresta, sempre em movimento. Os brancos chegaram e os Yaminawa sentiram medo daqueles seres perigosos e talvez canibais; os índios matavam brancos, os brancos matavam índios; depois mudou (na versão mais detalhada, trata-se de um menino Yaminawa raptado pelos brancos que, conhecendo as línguas de uns e outros, estabeleceu uma mediação) e desde então não há mais medo, os Yaminawa vão agora à cidade, seus jovens vão estudar com os brancos; agora há sal, açúcar e ferro, há roupas.

$\mathrm{Na}$ sua aparente simplicidade, e na monotonia com que essa sóbria narração se repete de um enunciador a outro, podem passar despercebidos inúmeros vínculos com aspectos estratégicos para se entender a diversidade cultural Yaminawa, como, por exemplo, o açúcar, o canibalismo e o machado de ferro. Além disso, o relato traz subentendido um paradoxo. Afinal, esse relato, que de certa forma oferece ao ouvinte estrangeiro uma narrativa histórica plausível dada sua absoluta verossimilhança, apresenta, em contrapartida, um caráter definitivamente paradigmático (e por isso, em certo sentido, ahistórico), já que, repetido sem variação apreciável de um narrador a outro, seja qual for a origem deste, descreve não um encontro com os brancos, mas O Encontro, em sentido genérico. Nada que individualize a "descoberta" dos Yaminawa entre centenas de episódios semelhantes, protagonizados por grupos indígenas de qualquer língua ou localização, por seringueiros, missionários ou agentes indigenistas. Poder-se-ia, talvez, alegar que de fato todos os encontros aconteceram segundo esse mesmo roteiro: a narração 
monótona de uma história monótona. Mas não seria essa uma das razões que levaram Euclides da Cunha a rotular a Amazônia como terra "à margem da história”? A reiteração dos mesmos episódios, das mesmas estratégias, das mesmas oposições século após século, não seria justamente o índice da falta de história nas regiões afastadas dos grandes centros de poder do mundo - os palcos da história propriamente dita?

Talvez a historicidade desse relato ganhe outro relevo se considerarmos que ele não só é, com efeito, uma narração sobre os brancos, mas sobretudo para os brancos. ${ }^{8}$

A primeira vez que o "relato do contato" me foi apresentado - por Clementino, consensualmente considerado o melhor conhecedor do acervo de shedipawó -, fiquei perplexo. A história da guerra e da paz com os brancos, da inicial carência e posterior fartura de mercadorias, figurava como a segunda parte de um relato que descrevia a aquisição da sexualidade reprodutora: os homens, que até então só tinham acesso à dobra posterior do joelho de suas companheiras, aprenderam do macaco prego a utilidade da vagina; desde então, os Yaminawa se multiplicaram.

Com esse relato híbrido, Clementino provavelmente buscava definir, de um lado, a relação entre os "relatos do contato" e o mundo dos shedipawó; de outro, o lugar do branco na cosmologia Yaminawa. Salta à vista o arranjo em paralelo de duas narrações que, em conjunto, dariam conta da situação atual dos Yaminawa. Em lugar de introduzir o "branco" como personagem em outras narrativas - isso nunca acontece -, em lugar de criar histórias manifestamente híbridas que pudessem ser lidas como mitificação da história ou historificação do mito, e em lugar de dedicar um relato a explicar a origem dos brancos, a solução adotada foi propor um paralelo entre dois episódios que descrevem a aquisição de saberes básicos dos animais e desse outro importante personagem. A maneira pela qual Clementino apresentou seu relato cumpriria assim uma dupla função: como todos os outros relatos sobre o contato joga com o reconhecimento do passado Yaminawa por parte dos brancos, com sua codificação das relações em termos de diferencial de mercadorias, os
Yaminawa, ou seus ancestrais imediatos, inseremse desse modo na história do ouvinte branco. Mas com o segundo segmento, o relato de Clementino insere também, metaforicamente, o branco dentro da tradição Yaminawa de fundar o mais íntimo de sua vida na absorção de saberes e técnicas estranhos. A descoberta do sexo reprodutivo, quem duvidaria, não cede em radicalidade a todas as mudanças que o homem branco introduziu. A vida dos Yaminawa experimentou muitas novidades nos últimos trinta anos; apenas a novidade em si é que não era nova em absoluto para eles.

O relato do contato, centrado na aquisição de saberes estranhos, poderia ser mais bem entendido em conjunto com uma outra narrativa, dirigida essencialmente ao interlocutor branco, e que poderíamos chamar de "relato do fim". Depois de falar eventualmente da perseguição, do cativeiro e do esbulho dos Yaminawa pelos brancos, e sobretudo da "entrega" desses índios aos invasores, tal narrativa centra-se no abandono de sua cultura tradicional e em suas conseqüências previsíveis. Declarações sobre a decadência cultural dos Yaminawa acompanharam minha pesquisa desde o início, complementadas com previsões bastante pessimistas acerca do futuro do grupo, que podem ser simbolizadas na seguinte frase: "daqui a trinta anos não haverá mais Yaminawa". Como no "relato do contato", é fácil reconhecer nesse tipo de declaração uma avaliação plausível, neste caso sobre o futuro do grupo; novamente, essa plausibilidade depende do uso de conceitos e diagnósticos bem conhecidos pelo ouvinte - um outro ouvinte, desta vez, não mais o agente do indigenismo oficial ou o patrão ou o seringueiro branco, mas o militante de uma ONG ou o antropólogo simpático às tradições alheias. Mais uma vez, o relato abre um nicho para os Yaminawa na história do interlocutor, garante um diálogo e uma eventual colaboração. Entretanto, seu conteúdo factual merece algumas ponderações em virtude da indefinição dessa "tradição" abandonada, assim como das condutas mais deletérias para o bom governo do grupo (brigas internas, constante deslocamento, cisões) que, relatadas em outros momentos como características dos "antigos", parecem mostrar de modo mais evidente a continuidade essencial dessa tradição "perdida". 
Em suma, podemos dizer que o papel do branco nos relatos shedipawó evoca em certo sentido o jogo que alhures as artes gráficas Pano estabelecem entre fundo e forma, o que permite a leitura de uma e outra trama no primeiro plano. À primeira vista, essas narrativas não fazem alusão alguma ao homem branco, ao contrário, descrevem um mundo livre de suas mercadorias, de seus deuses. De outro lado, tratam dele constantemente, isto é, a todo momento aparecem os nawa, os inimigos, ora semelhantes ora monstruosos "nawa" é o termo que designa os homens brancos e que atualmente denomina os outros por excelência. À primeira vista, não mais que uma homonímia, embora tenazmente mantida: ao reproduzir os relatos shedipawó ao idioma português, os Yaminawa costumam traduzir "nawa" por "branco", mesmo que isso tenha como resultado a aparição de "brancos" atirando flechas ou compartilhando a língua, os costumes ou os cordões penianos dos antigos. Mas será plausível supor uma simples homonímia quando se trata de um aspecto tão estratégico? Como já analisei em outro estudo (Calavia Sáez, 2002), o conjunto dos usos do termo "nawa" nos leva a uma conclusão contraintuitiva. Obcecados com a presença dos brancos, atraídos fatalmente por suas cidades e suas mercadorias, os Yaminawa não se deram ao trabalho de criar uma categoria nova para esse ser, mas optaram, antes, por lhe outorgar o usufruto de uma categoria central da sua cosmologia. Isso faz que o branco, de um lado, atraia para si a visão dos Yaminawa como acontece em todas as avaliações que se estendem sobre a deculturação do grupo - ou se torne invisível - como ocorre quando lemos o mundo Yaminawa através dos relatos shedipawó. Em qualquer caso, não há um marco que permita falar em antes e depois do branco; o nawa já existia antes da chegado do homem branco. É evidente que isso não faz do universo Yaminawa uma mónada surpreendentemente cega à ubiqüidade dos brancos - não haveria nenhum interesse em afirmar essa enormidade contra todo o senso COmum. Trata-se, pelo contrário, de notar que o conjunto das categorias usadas para descrever as relações possíveis no cosmos - que contava com a alteridade já em seu âmago - fica perfeitamente frio ante essa presença.

\section{Inventar a história}

Devo reconhecer que a historificação dos relatos shedipawó pode ser resultado do contexto narrativo, isto é, da pergunta acerca do passado Yaminawa que o motivou. Foi perguntando por história - e não, por exemplo, pedindo exegeses de tal ou qual prática - que obtive a coleção de narrações. ${ }^{2}$ Em outras palavras, minha pesquisa ofereceu uma oportunidade - pela primeira vez por escrito - para a invenção da história Yaminawa. Já aludi às suas duas principais versões - a dos shedipawó e a do relato do contato. Mas houve mais uma versão de características muito diferentes, formulada por quem dispunha de maior fluência na língua e nos modos discursivos do branco. O relato do chefe Correia, líder do grupo na ocasião, foi essencialmente uma lista de lugares e vizinhos: em tal lugar, os Yaminawa convivem com Shipibo, Piro e Catiana, em outro, com Sharanawa, Mastanawa e Marinawa; aqui, eles conhecem os peruanos, lá, ficam sabendo de índios selvagens que vivem escondidos na floresta. Entre uma e outra localização, como motor contínuo dessa história, surgiram conflitos que determinaram a saída dos ancestrais em direção a novos lares; em conflito com outros índios, eles viram também se multiplicar as divisões internas - os Yaminawa não são senão um conjunto de povos que só o homem branco tem decidido resumir nesse nome.

Pela ausência de elementos míticos e pela relevância das informações e dos conceitos obtidos no diálogo com indigenistas ou antropólogos (por exemplo, as noções sobre um tronco lingüístico Pano, ou os nomes dados aos antigos vizinhos peruanos), trata-se, sem dúvida, de um relato híbrido. Seria por isso um relato espúrio? O próprio enunciador é, biográfica e funcionalmente, um mestiço que durante muito tempo transitou entre a aldeia, a cidade e os seringais e que tanto assumiu o papel de chefe indígena como de chefe de posto. Mas deveríamos trazer para a historiografia indígena uma adaptação torpe da pureza étnica já descartada em outros âmbitos? Deveria a história indígena se limitar aos recursos da memória, descartando o uso de informações obtidas direta ou indiretamente de uma tradição escrita? O 
problema aqui não é se esse relato pode ou não ser considerado a legítima história yaminawa. Isso foi ao menos garantido na medida e no tempo em que o chefe-historiador o socializou entre seus seguidores. Mas ele é suficientemente "outro" para oferecer uma contribuição original, ou não passa de um reflexo, de uma reelaboração do escrito por outros, do saber depositado nas bibliotecas? Como em tantas outras ocasiões, a elucidação da história indígena recupera como problema um processo raramente tematizado, mas habitual em qualquer consciência histórica, a saber, a transformação em memória própria de informações obtidas de outrem. ${ }^{10}$ No caso indígena, a fronteira entre o próprio e o alheio, supostamente mais clara, sugere o paradoxo comum da fixação do factual mediante uma memória fictícia.

Cabe no entanto dizer que no relato de Correia há ingredientes valiosos dessa história "outra" que cobiçamos para além de dados inéditos na bibliografia recopilados nas memórias dos seus seguidores - o chefe é não só um narrador, mas também um pesquisador. Refiro-me à ordenação desses dados, os quais não se pode dizer que devam muito a qualquer uma das grandes narrativas da nossa historiografia, e menos ainda das que os nossos mediadores põem à disposição do historiador Yaminawa. Refiro-me em especial à definição do protagonista não a partir de uma origem, mas em contraste com seus "outros", que vão mudando de capítulo em capítulo: Shipibo, Catiana, Mastanawa etc. A narração do chefe Yaminawa apresenta um alto grau de sistematização: a história não é uma ilação de eventos, mas uma sucessão de estruturas - de relação interétnica - unidas, ou mais precisamente separadas, por eventos pontuais. Uma história em última análise consideravelmente fria, que leva as estruturas a gerar novas variantes de si mesma. ${ }^{11}$

\section{Nem reis nem batalhas}

Nenhum texto foi tão citado na bibliografia sobre história indígena dos anos de 1980 quanto os artigos de Marshall Sahlins sobre a história havaiana, especialmente sobre a dramática identificação entre o capitão Cook e o deus Lono. À parte de um argumento geral sobre a necessária articulação entre estrutura e história, Sahlins sublinha de modo provocativo a capacidade de reis e batalhas (marcos da depreciada histoire évenementielle) de encarnar e modificar estruturas duráveis. Também nessa rubrica a memória dos Yaminawa - à diferença da memória de muitos outros grupos indígenas - recusa oferecer satisfações imediatas ao pesquisador. Nos relatos do passado não há nomes próprios, não há personagens heróicos, não há monumentos; em suma, não há pontos de acumulação de informação que precisem ser reduzidos à estrutura. Mas esse perfil discreto em nada modifica aquela articulação a que Sahlins se refere, pelo contrário, a leva a terrenos mais necessários. ${ }^{12}$

No caso dos Yaminawa pode-se rastrear em pelo menos dois domínios clássicos do que costumamos considerar estruturas, a saber, a mitologia e o parentesco.

Quanto ao parentesco, não há dificuldade alguma em identificar a marca da história; mas sim, talvez, em reconhecer nela algum aspecto construtivo. É fácil perceber a diversidade de critérios no momento de classificar parentes, atribuir nomes, formular regras matrimoniais ou definir filiações ou agrupamentos. A precariedade dos dados genealógicos impede hierarquizar esses critérios ou medir sua efetividade. O parentesco seria assim - não faltam exegeses nesse sentido no seio do próprio grupo - um argumento em apoio da desorganização cultural e étnica dos Yaminawa, uma estrutura não articulada na história, mas desagregada por ela. Entretanto, será que o modo de articulação histórica das estruturas não está precisamente nesse contraste entre a ordem sempre discreta do passado (ou de um futuro postulado) e a pluralidade desordenada do presente? Quando se enuncia uma ordem autêntica, a autoridade moral do grupo - seja do chefe, seja dos velhos, seja ainda "daqueles que sabem" - lança mão em primeiro lugar desse contraste entre temporalidades, baseando o discurso sociológico no discurso histórico. A suposta "imobilidade" das estruturas advém de se identificar como "estrutura" esse modelo legitimado (isto é, "tradicional"), e não o conjunto de variantes em que ele ganha 
sentido. O sistema de parentesco Yaminawa, que oscila entre modelos dravidianos, australianos ou dakotas, não ilustra pois uma confusão entre ordens, senão o aspecto de conjunto de uma estrutura $^{13}$ na ausência de uma autoridade capaz de maximizar um desses aspectos sobre os outros, o que, em si, faz dos Yaminawa uma variante peculiar dentro do conjunto Pano, dotado de exemplos cristalinos de ordens "tradicionais". ${ }^{14}$ As possibilidades históricas da estrutura não residiriam na sua capacidade de responder a acontecimentos externos, ou de se desdobrar neles, mas justamente na sua variabilidade interna, que permite, ou obriga, diversas leituras consecutivas. Os acontecimentos históricos - os reis e as batalhas de Sahlins - seriam, assim, fundamentalmente pontos discretos de releitura de uma estrutura suscetível de muitas versões.

Quanto à mitologia, é evidente o seu caráter de obra aberta. Parece claro que determinadas narrativas foram improvisadas para o pesquisador, com base em algumas fórmulas conhecidas que permitiam faze-lo sem muito esforço. A comparação dos mitos Yaminawa com seus correlatos de grupos Pano muito próximos mostra, para além de uma surpreendente continuidade de temas e argumentos, a facilidade com que esses mitos vêm se transformando, acompanhando alterações em outros âmbitos, como o do parentesco e o da autoridade política. Em diversos artigos (Calavia Sáez, 2000, 2001, 2002, 2003) tenho tentado mostrar como os mitos Yaminawa são capazes de sintetizar os contrastes que opõem esse grupo a outros com os quais compartilha um mesmo acervo narrativo, tanto na montagem de episódios e na caracterização de personagens, como no estilo e no contexto de enunciação. Em outras palavras, trata-se de uma mitologia inequivocamente yaminawa, cuja coerência surpreende: coligidos de um número elevado de informantes, procedentes de grupos diferentes e que poderiam fazer da oralidade Yaminawa uma federação de tradições particulares, esses mitos formam, pelo contrário, um acervo bastante consolidado. As variações que podemos perceber entre as diversas versões, apesar da diferença de estilos entre os narradores, são mínimas, o que garante relatos homogêneos em contraste com as narrativas de povos muito próximos. Essa divergência ordenada em relação a outras mitologias vizinhas sugere que os mitos Yaminawa estão longe de representar um material conservador. Muito pelo contrário, são especialmente sensíveis ao curso da história e permitem ao pesquisador detectar tendências pouco reconhecíveis em outros campos da vida social yaminawa. Maleáveis para o narrador, mas submetidos a um processo de comunicação que descarta ou normaliza as novidades, isto é, que as estrutura. Não é surpreendente que, a partir de Lévi-Strauss, uma versão móbil da noção de estrutura que não se opõe à mudança, mas que a exige como condição permanente, tenha se baseado precisamente nos mitos. Em última análise, que melhor lugar para esse curso da história senão um modo cambiante de contá-la? Os mitos Yaminawa são história não porque abarquem informações inéditas e irredutíveis sobre o passado, mas porque o reformulam constantemente. Fazem-no agora e nada indica que não o tenham feito anteriormente.

\section{A terceira margem}

A história, submetida às condições do caso Yaminawa, tem a possibilidade de recuperar algumas feições originais. E não porque permite grandes aproximações entre nosso relato histórico e um relato histórico de outro tipo; antes, nos devolve, reformulada, a distância estabelecida entre os povos com ou sem história. O que os Yaminawa nos narram carece desses marcos que habitualmente têm servido como pedras de Rosetta na interpretação das memórias indígenas como história: grandes acontecimentos, divisão em grandes períodos. Além disso, a própria precariedade dos documentos referidos aos Yaminawa e a indeterminação de uma identidade transtemporal impedem que pensemos o discurso Yaminawa sobre o passado como uma "tomada de consciência" de uma história já existente. Dirigidos ao homem branco, e elaboradas com um uso generoso de seus termos, as narrativas Yaminawa mostram freqüentemente a história como invenção. Essa ausência de uma historia "dada" - da qual o discurso his- 
tórico construído seria um reflexo mais ou menos fiel - sublinha em contrapartida dois aspectos importantes que costumam não aparecer na historiografia dos povos "com história". O primeiro diz respeito ao papel relevante que saberes outros adquirem nesses relatos, ou seja, a história entendida como narração de outros ou sobre outros. O segundo concerne ao papel essencial que o discurso histórico assume na história em si: não como reflexo dela, mas como fator de primeira linha na sua prática. A formulação da história dissimula sua eficiência quando encomendada a um corpo de especialistas distantes do palco político, e assim, paradoxalmente, à margem da história, mas se mostra a plena luz quando, em função de uma liderança política, passa a ser entendida como um acontecimento central. ${ }^{15}$ Nesse ponto estratégico, o discurso histórico ocupa, para os povos indígenas, o mesmo lugar em que se encontra a absorção de alteridade via a aliança matrimonial e o ingresso de mercadorias ou doutrinas, além de estar provavelmente sujeito aos mesmos filtros cosmológicos que regulam essas outras incorporações. Os povos indígenas absorvem a história alheia não porque careçam dela, mas porque a submetem ao mesmo regime de subjetivação que é aplicado ao material sociológico, ideológico ou técnico.

Mas a ausência na história Yaminawa de grandes acontecimentos, de reis, batalhas e seqüências temporais - em suma de motivos narrativos - serve para que a história se localize onde ela está dada, antes da sua elaboração narrativa, isto é, na variabilidade mandatória das estruturas, que só podem ser percebidas em seu contraste e em sua alteração. A alteração é, pois, o estado normal; ao contrário da estabilidade primitiva (entre os Yaminawa sempre se espera que a autoridade de um chefe seja capaz de implementar na realidade ou na memória tal estabilidade), ela é um fruto selecionado da história que nem sempre amadurece.

Retomando o início deste artigo, lembremos que a reivindicação da história indígena se deu em duas frentes: a da historicidade objetiva dos povos indígenas (que não são imagens congeladas de um estado primitivo) e a da sua subjetivação, isto é, a presença de um saber histórico e, portanto, de uma consciência histórica peculiar. Parece claro que essas dimensões devem estar articuladas, isto é, a constatação de que a maneira pela qual os povos percebem e narram sua história é parte essencial dessa história. É nesse ponto que podemos perceber quão errada foi a leitura do binômio sociedades frias/sociedades quentes como uma negação da história, quando deveria ter sido considerado justamente a chave para a elucidação do contraste entre historicidades diversas. Apenas os relatos propagandísticos do Progresso, das Luzes ou da Revolução - cuja importância não deve ser desdenhada, pois cumprem um papel muito importante no percurso dos povos "com história" - fazem da distinção entre quente e frio uma questão de dados. Na prática, os dados só aparecem ordenados em relatos, que são os que definem o seu valor. É assim que revoluções se travestem de restaurações, e restaurações de revoluções; é assim que tudo muda para que tudo permaneça igual, e que as grandes mudanças atuam como velhas toupeiras socavando um solo aparentemente imutável. Entretanto, somente a concepção de Lévi-Strauss ${ }^{16}$ tendia a fazer desse jogo não uma astúcia da história, mas uma ação humana suscetível de versões alternativas. Para entender as manipulações da temperatura histórica é preciso perceber que, na versão lévi-straussiana, as estruturas são incapazes de dar conta de ambos os feitos que se lhes atribui: o de permanecer incólumes (constituídas de contradições entre os termos - sua estabilidade seria uma contradição nos termos) e o de abolir-se para dar lugar a estruturas absolutamente novas (seus termos são demasiado básicos para que se possa imaginar uma nova configuração que prescinda deles). A comparação dos contrastes existentes no relato histórico é que torna possível perceber que a história, quer se trate de revoluções, quer se trate de permanências, é sobretudo um efeito de sentido, amplamente eficaz sobre a realidade.

A terceira margem da história é habitada por esse historiador orgânico que seleciona dados, ritmos e direções, que determina o frio ou o calor do relato. Talvez, mais do que encontrar história lá onde alguém supôs que ela não existisse, no estudo da história indígena é importante reencon- 
trar, na invenção do sujeito, na variação mítica, na mimese de outros relatos, os traços vivos originais da prática da história, tantas vezes apagados pela rotina da historiografia.

\section{NOTAS}

1 Estou pensando sobretudo em atividades como os Grupos de Trabalho (GTs) sobre história indígena nas reuniões da ABA e da Anpocs, a elaboração do Guia de Fontes sobre a História Indígena no Brasil, e em grupos especializados como o Núcleo de História Indígena e do Indigenismo, criado na USP por Manuela Carneiro da Cunha. Contudo, muitas outras iniciativas individuais ou coletivas trilharam esse campo nesse período, embaladas por um interesse geral em relação a temas como, por exemplo, a memória e a história oral, considerando esta um método e um movimento político-cultural.

2 Não cabe no espaço restrito deste artigo uma avaliação geral - de resto, muito necessária - da extensa bibliografia sobre história indígena produzida nos últimos decênios. Ver mais detalhes da revisão aqui esboçada em Viveiros de Castro et al., 2003.

3 Somente depois de uma presença continuada de pregadores/pesquisadores do ILV que aflora com notável clareza um modelo Kaxinawá que não se reconhecia em documentos mais antigos. Ver Calavia Sáez (2000, pp. 25-27).

4 Uma boa oportunidade não é necessariamente a única oportunidade. Qualquer reconstrução de longo prazo do passado Pano (ver Lathrap et al., 1985) adverte a existência de contatos muito anteriores ao dos brancos e, sem dúvida, não menos dramáticos.

5 Esse sujeito impossível da história Yaminawa acrescenta uma nova dimensão às discussões sobre a possibilidade de uma história ou de uma agência histórica "sem sujeito" (cf. Palti, 2004); a alternativa sujeito/não sujeito estaria "na história" e não somente na teoria da história.

6 De maneira significativa, o xamanismo, tão intimamente ligado a esses relatos, é uma atividade afastada da esfera pública.
7 Algo parecido acontecia com os relatos protagonizados exclusivamente por animais, que de um lado pareciam ficar fora do campo dos shedipawó stricto sensu, mas que ao mesmo tempo acabavam se alinhando a eles, na falta de uma categoria específica na qual se pudesse inseri-los.

8 O destinatário, e o contexto que ele aporta, é raras vezes levado em consideração ao se tratar de história indígena. O trabalho de Gow (2001) é uma exceção notável, útil também para apreciar a relevância do improviso nesse diálogo histórico.

9 No entanto, é preciso dizer que, durante a pesquisa, foram oferecidas também oportunidades ao discurso exegético, mas não se obteve resultados apreciáveis. A historificação das narrativas não se deu às custas de um hábito exegético recalcado. Ademais, a exegese acontecia eventualmente por meio da historificação - uma restrição alimentícia, por exemplo, deveria ser um costume dos antigos, porque havia um relato que fazia tal referência.

10 Em contrapartida, a oralidade eminente atribuída naturalmente à história indígena dissolve um outro problema que na historiografia escrita se deixa captar melhor, a saber, o do esquecimento. Saber quais dados foram apagados da memória pode ser tão revelador quanto a memória preservada em si. Essa vertente da historiografia indígena continua inédita, embora não faltem dados para explorá-la.

11 Vale dizer, porém, que no relato em pauta essas variações tinham uma direção definida: a do progressivo isolamento e desagregação dos Yaminawa.

12 Segundo uma crítica recente de Peter Gow (2001, p. 18), as análises de Sahlins mostram mais a possibilidade de dar valor antropológico a acontecimentos históricos do que um modo de se fazer história a partir de estruturas.

13 Sobre a possibilidade, ou a necessidade, de convivência desses sistemas, cf. Viveiros de Castro, 1995.

14 O que equivale a sugerir (seguindo a referência clássica de Leach sobre a Alta Birmânia) que esse conjunto deve ser lido como um sistema de situações políticas, e não só como um agregado de etnias.

15 Essa situação se equivalente, no nosso caso, se a presidentes e reis correspondesse constitucional- 
mente a enunciação da história oficial. Algo, afinal, não tão longe assim da nossa experiência: basta lembrar que a primeira História General da Espanha leva a assinatura do rei Alfonso X, que Thiers foi um historiador importante e que o imperador Pedro II teve um papel relevante na formulação de uma história do Brasil. A desatenção para os elos entre acontecimento e estrutura, porém, podem levar o estudioso a imaginar tais empresas como uma espécie de atividade de lazer.

16 O binômio de Lévi-Strauss parte da textura sociológica das sociedades, e não da percepção e do relato da história. Estes últimos são abordados principalmente na sua polêmica com Sartre (LéviStrauss, 1962).

\section{BIBLIOGRAFIA}

CALAVIA SÁEZ, O. (1995), O nome e o tempo dos Yaminawa. Tese de Doutoramento apresentada na FFLCH-USP.

. (2000) "O Inca Pano: mito, história e modelos etnológicos". Mana, 6 (2): 735.

. (2001), "El rastro de los pecaríes: variaciones míticas, variaciones cosmológicas e identidades étnicas en la etnología Pano". Journal de la Societé des Américanistes, 87: 161-176.

. (2002), "Nawa, I-nawa". Ilha, 4 (1): 35-57, Florianópolis, PPGAS.

. (2003), "Extranjeros sin fronteras: alteridad, nombre e historia entre los Yaminawa”. Anuario Indiana, 19 (20): 73-88. Berlim, Ibero-Amerikanischer Institut.

CARNEIRO DA CUNHA, M. (1992), "Introdução a uma história indígena”, in História dos índios no Brasil, São Paulo, Companhia das Letras.

CHARBONNIER, G. (1989), Arte, linguagem, etnologia: entrevistas com Claude LéviStrauss. Campinas, Papirus.
FRANK, Erwin. (1991), "Etnicidad: contribuciones etnohistóricas a un concepto difícil”, in Jorna, Malaver e Oostra, Etnohistoria del Amazonas, Quito, Abya-Yala.

GOW, P. (2001), An Amazonian myth ad its history. Oxford, Oxford University Press.

LATHRAP, D.; GEBHART-SAYER, A. \& MESTER, A. (1985), "The roots of the Shipibo art style: three waves on Imiriacocha or there were Incas before the Incas". Journal of Latin American Lore, XI: 31120.

LÉVI-STRAUSS, C. (1962), "Histoire et dialectique”, in _La pensée sauvage, Paris, Plon.

. (1987), "O campo da antropologia", in Antropologia estrutural II, Rio de Janeiro, Tempo Brasileiro.

PALTI, E. (2004), "The "Return of the Subject" as a historico-intellectual problem". History and Theory, 43: 57-82.

VIVEIROS DE CASTRO, E. (1995), “Ambos os três: sobre algumas distinções tipológicas e seu significado estrutural na teoria do parentesco". Anuário Antropológico, pp. 9-91.

VIVEIROS DE CASTRO, E. et al. (2003), Transformações indigenas: os regimes de subjetivação ameríndios à prova da história. Projeto Pronex (mimeo.).

WAGNER, R. (1975), The invention of culture. Chicago, The University of Chicago Press. 


\section{A TERCEIRA MARGEM DA HISTÓRIA: ESTRUTURA E RE- LATO DAS SOCIEDADES INDÍ- GENAS}

Oscar Calávia Sáez

Palavras-chave

Teoria antropológica; História; Etnohistória; Sociedades frias; Yaminawa.

A partir dos resultados da pesquisa realizada pelo autor entre os Yaminawa do Acre, este artigo faz uma investigação histórica a respeito dos povos indígenas no Brasil. É possível formular algumas questões sobre o papel que cabe a essa historiografia no quadro teórico geral da antropologia. A história dos povos indígenas veio nos dizer algo novo a respeito deles, ou veio, antes, afirmar algo sobre uma antropologia que, durante muito tempo, se apoiou, de modo mais ou menos explícito, na distinção entre uma humanidade "com" e outra "sem" história? Assistimos, simplesmente, à dissolução de mais uma falsa dicotomia, ou talvez essa dicotomia era demasiado produtiva para não desaparecer sem deixar atrás de si uma modificação profunda dos seus termos?

\section{THE THIRD SHORE OF HIS- TORY: STRUCTURE AND NAR- RATIVE OF THE INDIGENOUS SOCIETIES \\ LA TROISIÈME RIVE DE L'HIS- TOIRE: STRUCTURE ET RÉCIT DES SOCIÉTÉS INDIGÈNES}

Oscar Calávia Sáez

\section{Keywords}

Anthropological theory; History; Ethnohistory, Cold societies; Yaminawa.

From the point of view of my own research among the Yaminawa of the Acre River, this paper examines the latest historiography on the indigenous peoples in Brazil - a rather new discipline, since these peoples were viewed as "out of history" not long ago. It brings some questions on the role that the historicity of indigenes plays in the broader theoretical frame of anthropology. Does it tell us anything new about "natives" or about this anthropology that has been leaned, more or less explicitly, in the distinction between humanity "with" and "without" history? Have we either faced the dissolution of another false dichotomy or perhaps such dichotomy used to be too much productive not to have disappeared without leaving behind a profound modification of its terms?

\author{
Oscar Calávia Sáez
}

\section{Mots-clés}

Théorie anthropologique; Histoire; Ethnohistoire; Sociétés froides; Yaminawa.

À partir des résultats des recherches développées parmi les indiens Yaminawa, de l'État brésilien de l'Acre, l'auteur propose une investigation historique des peuples indigènes au Brésil. Quelques questions se posent à propos du rôle de cette historiographie dans le cadre théorique de l'anthropologie: l'histoire des peuples indigènes nous enseigne quelque chose de nouveau en ce qui les concerne ou, plutôt, sur une anthropologie qui, pendant longtemps, s'est fondée, de façon plus ou moins explicite, sur la distinction entre une humanité "avec" et une autre "sans" histoire? Sommes-nous tout simplement face à la dissolution d'une autre fausse dichotomie, ou cette dichotomie était-elle trop productive pour ne pas disparaître sans laisser derrière elle un changement profond dans son contenu? 